\title{
Production and characterization of bacterial cellulose-alginate biocomposites as food packaging material
}

\author{
${ }^{1,3}$ Agustin, S., ${ }^{2}$ Wahyuni, E.T., ${ }^{1}$ Suparmo, ${ }^{1}$ Supriyadi and ${ }^{1, *}$ Cahyanto, M.N. \\ ${ }^{1}$ Department of Food and Agricultural Product Technology, Faculty of Agricultural Technology, \\ Universitas Gadjah Mada, Jalan Flora, Bulaksumur, Yogyakarta 55281, Indonesia \\ ${ }^{2}$ Department of Chemistry, Faculty of Mathematics and Natural Sciences, Universitas Gadjah Mada, Jalan \\ Sekip Utara, Bulaksumur, Yogyakarta 55281, Indonesia \\ ${ }^{3}$ Department of Agricultural Product Technology, Faculty of Agriculture, Mulawarman University, Jalan \\ Pasir Balengkong, Samarinda 75117, Indonesia
}

\author{
Article history: \\ Received: 14 December 2020 \\ Received in revised form: 11 \\ February 2021 \\ Accepted: 16 May 2021 \\ Available Online: 19 \\ December 2021
}

Keywords:

Bacterial cellulose,

Alginate,

Biocomposite

DOI:

https://doi.org/10.26656/fr.2017.5(6).733

\begin{abstract}
Biocomposite of bacterial cellulose-alginate has been developed for use as food packaging material. This study aims to understand the physical and mechanical properties of the biocomposite produced from static fermentation of Gluconacetobacter xylinus InaCC B404 in media supplemented with alginate. The strain was grown in a medium containing alginate at a concentration of $0.4,0.8$, and $1.2 \% \mathrm{w} / \mathrm{v}$ at $30^{\circ} \mathrm{C}$ for 7 days. The SEM images showed that bacterial cellulose produced in a medium supplemented with alginate had a denser structure of fibril network and a smaller pore size than the control one. The structure change was due to interactions through hydrogen bonds between bacterial cellulose and alginate proven by FTIR spectra, resulting in a decrease in crystallinity and crystallite size of bacterial cellulose. It led to the decrease in tensile and tear strength of the resulting biocomposite. Alginate also causes biocomposite to have higher water vapour permeability values.
\end{abstract}

\section{Introduction}

Over the past few decades, there has been a rising interest in research on composite materials from natural polymeric materials, especially those aimed at environmentally friendly food packaging materials. Natural polymers such as polysaccharides are widely explored as biocomposite materials because of their abundant availability, low cost, and mostly soluble in water which makes them easy to apply (Debeaufort et al., 1998; Cazon et al., 2017).

Cellulose is a high molecular weight polysaccharide composed of glucose units connected by $\beta-1,4$ glycosidic bonds with three hydroxyl groups in each glucose unit. Bacterial cellulose is an exopolysaccharide produced by Gluconacetobacter xylinus bacteria. Bacterial cellulose is chemically identical to plant cellulose, with several advantages including high purity and naturally occurring in the form of nano-sized fibres. This causes bacterial cellulose does not require purification stages or other treatments to obtain nano-sized fibres (Ruka et al., 2012). Other characteristics of bacterial cellulose are high mechanical strength and crystallinity (Martins et al.,
2009), so they have high rigidity. Coatings and films produced from cellulose derivatives are reported to have strong, transparent, odourless, tasteless, resistant to fats and oils, highly biodegradable, efficient barrier to $\mathrm{O}_{2}$, $\mathrm{CO}_{2}$, and aroma, but moderate resistance to moisture (Villalobos et al., 2005; Vargas et al., 2008).

The weaknesses of most biopolymers which are mechanical characteristics such as brittle, stiff and high permeability to gas and water vapor, can be overcome by developing biocomposite technology. Bacterial cellulose -based biocomposites can be developed through a bottom -up technique, namely by integrating a second biopolymer compound into the bacterial cellulose matrix during the cultivation process. The incorporation of additional nutrients in the form of compounds from polysaccharide groups such as alginate to the fermentation media will modify the structure, morphology and characteristics of bacterial cellulose produced by interfering with the cellulose crystallization and polymerization processes (Grande et al., 2009) so that bacterial cellulose biocomposites are produced with different characteristics from its natural bacterial cellulose. 
Alginate is the most common polysaccharide found in brown seaweed (up to $40 \%$ dry weight) (Gholamipoor et al., 2013), a hydrophilic colloidal carbohydrate extracted using an aqueous alkaline solution. Alginates consist of monomer units of $b$-D-manuronic acid residue (M) and $\alpha$-L-guluronic acid (G) connected by $(1,4-)$ bonds. Alginate is the only polysaccharide that contains carboxyl groups in each of its constituent residues and has a variety of functional properties for various applications as functional materials. Alginate is generally used as a thickener, forming a suspension, forming a film layer and emulsion stabilizer (Rhim et al., 2013).

Modification of bacterial cellulose by polysaccharides was first carried out by Ben-Hayyim and Ohad (1965) through the addition of CMC (carboxymethyl cellulose) which is known to delay cellulose aggregation. Cienchanska (2004) added chitosan to the growth medium of cellulose-producing bacteria for application in the medical field, while Seifert et al. (2004) produced modified bacterial cellulose in a medium supplemented with carboxymethylcellulose, methylcellulose and poly (vinyl alcohol) to obtain bacterial cellulose with controlled water content for medical biomaterials.

The development of bacterial cellulose-based biocomposites has been widely carried out, but its application in the field of food especially as the packaging of food products is still very limited. This research is aimed to study the physical and mechanical properties of biocomposites resulting from the fermentation of G. xylinus bacteria in media added with alginate and its potential as a packaging material for food products.

\section{Materials and methods}

\subsection{Materials}

The bacteria used was Gluconacetobacter xylinus InaCC B404 obtained from the Indonesian Culture Collection (InaCC). The strain was cultured in HestrinSchramm (HS) agar containing 2\% D-glucose, $0.5 \%$ peptone, $0.5 \%$ yeast extract, $0.27 \% \quad \mathrm{Na}_{2} \mathrm{HPO}_{4}$ and 0.115\% citric acid monohydrate (Hestrin and Schramm, 1954).

\subsection{Bacterial cellulose production}

Seed cultures of G. xylinus were inoculated into 10 $\mathrm{mL}$ of HS broth, incubated for 3 days at $30^{\circ} \mathrm{C}$ under static conditions. The resulting culture was then shaken vigorously to release the cells from the cellulose pellicles formed. A $5 \%(\mathrm{v} / \mathrm{v})$ cell suspension was inoculated into $100 \mathrm{~mL}$ of HS medium in a $500 \mathrm{~mL}$ conical flask and incubated for 3 days at $30^{\circ} \mathrm{C}$ under static conditions. The cell suspension obtained was then used as a starter to produce cellulose. Cellulose production was carried out in $1 \mathrm{~L}$ HS media supplemented with alginate at various concentrations $(0.4,0.8$, and $1.2 \% \mathrm{w} / \mathrm{v})$ with inoculation of $15 \%$ G. xylinus cell suspension (starter) into the media. Cultures were grown at $30^{\circ} \mathrm{C}$ for 7 days under static conditions. After the incubation period was completed, the formed pellicles were harvested and boiled in $0.1 \mathrm{~N} \mathrm{NaOH}$ for 30 minutes followed by a washing process with distillate water until neutral $\mathrm{pH}$ was achieved. This process aims to eliminate the remaining culture media and microorganisms. For the purposes of morphology, functional groups, crystallinity, mechanical properties, opacity and water vapor permeability analysis, the harvested pellicles were dried using the freeze-drying method for 15-24 hrs.

\subsection{Morphology}

Observation of the biocomposite surface morphology was carried out using a Scanning Electron Microscope (JEOL JSM6510 LA). The freeze-dried biocomposite was installed in a bronze visualization section with double-site tape. The sample surface was coated with a thin gold layer at $60 \mathrm{~s}$ sputter time and $15 \mathrm{~mA}$ sputter current. The sample was inserted into the SEM tool and its surface image was taken with a SE (Secondary Electron) detector, the working distance (WD) 11.5-12 $\mathrm{mm}$ and EHT $11 \mathrm{kV}$.

\subsection{Functional groups}

Analysis of molecular function group bonds and changes in absorption bands was performed using FTIR Spectroscopy (Shimadzu-8201 PC Corp., Japan) at wavenumbers $400-4000 \mathrm{~cm}^{-1}$ with a resolution of 4 $\mathrm{cm}^{-1}$. Sample analysis was performed by mixing $2 \mathrm{mg}$ of the sample with $\mathrm{KBr}$ powder $(0.4 \mathrm{~g})$ to further make $\mathrm{KBr}$ -IR pellets. All spectra were recorded at room temperature conditions. Specifically, this procedure produces spectra data showing the relationship between $\%$ transmittance and wavenumber.

\subsection{Crystallinity and crystallite size}

XRD analysis technique was intended to determine the crystallinity index and crystallite size of the $\mathrm{BC}$ and BCA samples. The XRD pattern of the sample was recorded using Rigaku Miniflex600 at $\mathrm{CuK} \alpha$ radiation wavelength $(\lambda=1.54 \AA), 40 \mathrm{kV}$ voltage and $15 \mathrm{~mA}$ filament emission. The sample was measured in the range of $2 \theta$ values between $0-80^{\circ}$. Crystallinity index (Cr) value was calculated based on peak intensity with the following formula:

$$
\operatorname{Cr}(\%)=\frac{S c}{S t} \times 100 \%
$$


Where $\mathrm{Sc}$ is the area of the crystalline region and $\mathrm{St}$ is the whole area. The size of the crystallite $(\mathrm{CrS})$ is calculated using the Scherrer equation as follows:

$$
\operatorname{CrS}=\frac{K \lambda}{\beta \cos \theta}
$$

Where $\mathrm{K}$ is the form factor of the crystal (0.9), 1 is the wavelength of $\mathrm{X}$ rays $(1.54 \AA), \beta$ is FWHM (full width at half maximum, $\mathrm{rad}$ ) and $\theta\left(^{\circ}\right)$ is the diffraction angle.

\subsection{Water vapour permeability}

The water vapour permeability (WVP) analysis was performed referring to the ASTM E 96-95 (1995) method with modification. The film sample was cut in a circle shape with a diameter of $12 \mathrm{~mm}$ and attached to the mouth of a test tube that has been filled with distilled water by a quarter of the volume of the tube. The tube was weighed and placed in a dry cabinet with a certain temperature and humidity. Changes in tube weight due to reduced water vapour in the tubes were known through weighing at 30 mins intervals for $2.5 \mathrm{hrs}$. The water vapour transmission rate (WVTR) is calculated through the linear regression slope of the weight vs. time curve. Water vapor permeability was calculated using the following equation:

$$
W V P=\frac{W V T R \times t}{A x P(R 1-R 2)}
$$

Where $\mathrm{t}=$ film thickness $(\mathrm{m}), \mathrm{A}=$ film area $\left(\mathrm{m}^{2}\right), \mathrm{P}=$ saturated water vapor pressure, R1-R2 = difference in RH inside and outside the tube.

\subsection{Mechanical properties}

The mechanical properties of the film namely tensile and tear strength were measured using a Universal Testing Machine (UTM) ZWICK Z.05-type mechanical tester based on ASTM - D882-12 (2012). Film width of $2 \mathrm{~cm}$ and length of $10 \mathrm{~cm}$ was prepared by using a precise cutter and then inserted into the locking grip. Each sample specimen was stretched at test speed of 10 $\mathrm{mm} / \mathrm{min}$ until constant strain rate was reached.

\subsection{Opacity}

Measurement of film opacity was done by referring to Wang et al. (2018). Film samples were cut to size according to the shape and size of the cuvette used. Opacity was measured using a UV-Vis spectrophotometer at a wavelength of $600 \mathrm{~nm}$. The opacity value is calculated using the following equation.

$$
\text { Opacity }=A b s_{600} / X
$$

Where $\mathrm{Abs}_{600}$ is the absorbance value at a wavelength of $600 \mathrm{~nm}$ and $\mathrm{X}$ is the thickness of the film sample (mm).

\subsection{Statistical analysis}

The data obtained were analysed using the One-Way ANOVA method using SPSS Version 25 Statistics Software (2017). The level of significance was set at $\alpha=$ 0.05 .

\section{Results and discussion}

\subsection{Morphology}

Bacterial cellulose (BC) samples showed a structure in the form of a network with many fibres, which consists of several layers of interlocking fibrils (Figure 1a). BC also shows a more porous structure than bacterial cellulose - alginate (BCA). BC and BCA 1.2\% $(\mathrm{w} / \mathrm{v})$ (Figure 1c) have a smooth surface structure, while BCA 0.4 and $0.8 \%(w / v)$ (Figure 1a and $1 \mathrm{~b}$ ) have a rough surface structure as shown in Figure 1. SEM photo results of BCA $1.2 \% \quad(\mathrm{w} / \mathrm{v})$ showed that alginate incorporated in the cellulose fibrils network, hence produced a denser film with a smaller pore sizes than $\mathrm{BC}$, resulting in films with finer surface structure. The difference in morphological structure obtained can be caused by differences in orientation of the fibril and fibril width of each sample. The presence of flocculation, agglomeration and fusion in the drying process also affects the morphology of the biocomposite produced (Chiaoprakobkij et al., 2011).
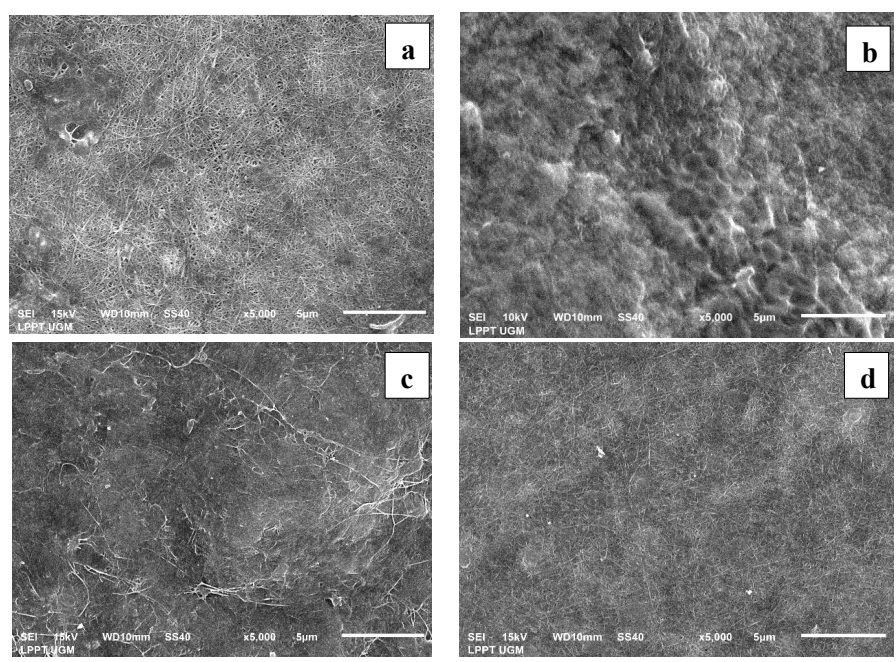

Figure 1. SEM surface images of BC (a), BCA $0.4 \% \mathrm{w} / \mathrm{v}(\mathrm{b})$, BCA $0.8 \% \mathrm{w} / \mathrm{v}(\mathrm{c})$ and BCA $1.2 \% \mathrm{w} / \mathrm{v}(\mathrm{d})$

\subsection{Functional groups}

FTIR spectroscopy method is applied to the sample to determine any peak changes that occur due to interactions between two or more polymers, through the formation of hydrogen bonds and/or complex compounds (Zhou et al., 2007). Figure 2 shows the FTIR spectrum produced by bacterial cellulose with or without the addition of alginate in the range of wavenumbers from $400-4000 \mathrm{~cm}^{-1}$. In the $\mathrm{BC}$ spectrum there were vibrations at wavenumber $3410 \mathrm{~cm}^{-1}$ which indicate 
stretching $\mathrm{OH}$ groups, vibrations at wavenumber 1645 $\mathrm{cm}^{-1}$ which indicate shrinkage of the carbonyl group from glucose monomers, and vibrations at wavenumber $1064 \mathrm{~cm}^{-1}$ indicating the stretching of the C-O-C and C$\mathrm{O}-\mathrm{H}$ groups from the glucose ring. Meanwhile, the BCA spectrum showed a peak at $3345.42-3356.96 \mathrm{~cm}^{-1}$ for stretching of the hydroxyl group. A shift in vibration absorption stretches the hydroxyl bond to a lower wavenumber, the hydroxyl stretching band also becomes wider with the addition of alginate. This indicates the intermolecular interaction between $\mathrm{BC}$ and alginate (Miao and Hamad, 2013).

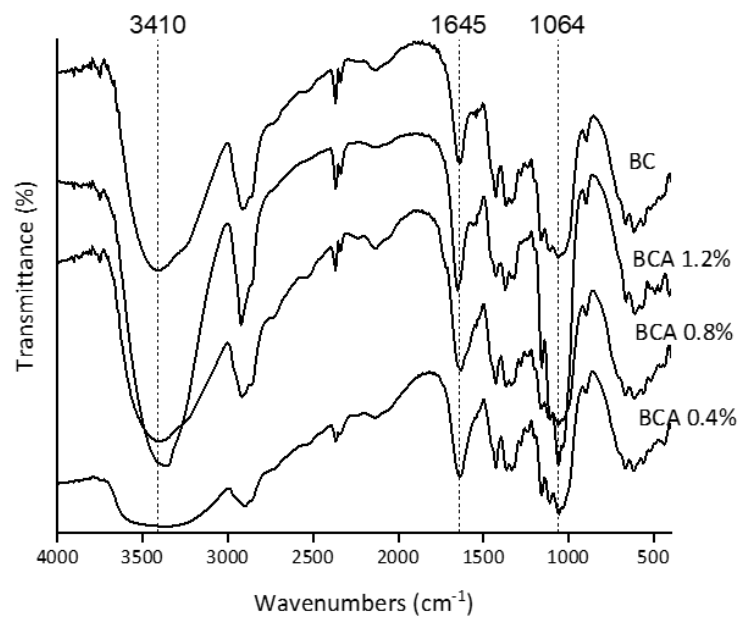

Figure 2. FTIR spectra of $\mathrm{BC}$ with different concentrations of alginate

The interaction of $\mathrm{BC}$ and alginate can also be identified through the carbonyl and carboxyl group bands at wavenumbers $1500-1900 \mathrm{~cm}^{-1}$ (Chiaoprakobkij et al., 2011). The absorption band of the carboxyl group shifted from $1635.64 \mathrm{~cm}^{-1}$ on $\mathrm{BC}$ to $1653.57 \mathrm{~cm}^{-1}$ at $1.2 \%(\mathrm{w} / \mathrm{v})$ BCA. This shift can be caused by intermolecular interactions between hydroxyl groups in $\mathrm{BC}$ with carboxyl groups in alginates, which ultimately disrupt hydrogen bonds between cellulose fibres (Chiaoprakobkij et al., 2011). Similar results were also obtained on BC/alginate composites (Chiaoprakobkij et al., 2011; Sya'di et al., 2017), membranes from cotton cellulose /alginate mixtures (Yang et al., 2000) and BC/ alginate mixed membranes (Phisalaphong et al., 2008).

\subsection{Crystallinity and crystallite size}

$\mathrm{X}$-ray diffraction patterns from $\mathrm{BC}$ and $\mathrm{BCA}$ films show peaks which are characteristic of bacterial cellulose, with BCA peak intensities smaller than BC (Figure 3). The two peaks detected in $\mathrm{BC}$ revealed $2 \theta$ values of $14.58^{\circ}$ and $22.72^{\circ}$ referring to polymorphs of cellulose $\mathrm{I} \alpha$ and $\mathrm{I} \beta$ (fields $100_{1 \alpha}, 110_{1 \beta}$ and $010_{1 \beta}$ at $15^{\circ}$ and $110_{1 \alpha}$ and $200_{1 \beta}$ at $22.5^{\circ}$ ). The presence of alginate in the BCA did not change the X-ray diffraction pattern but changed the intensity and width of the peak. This indicates that the addition of alginate did not affect the crystalline structure of the $\mathrm{BC}$ matrix (Xiang and Acevedo, 2017). The addition of alginate causes a decrease in crystallinity and crystallite size of the biocomposite produced as can be seen in Table 1 . Interactions in the form of hydrogen bonds between cellulose crystals and alginate can cause a decrease in cellulose crystallinity (Ul-Islam et al., 2012). BC crystallinity is related to inter- and intramolecular hydrogen bonds formed during $\mathrm{BC}$ aggregation stages, starting from subfibrils, microfibrils to pellicles forming. Polysaccharides added to the medium can inhibit the BC aggregation process and change the intramolecular hydrogen-bonding pattern in the $\mathrm{BC}$ produced, depending on the type, molecular weight and the amount of polysaccharide added (Hirai et al., 1998).

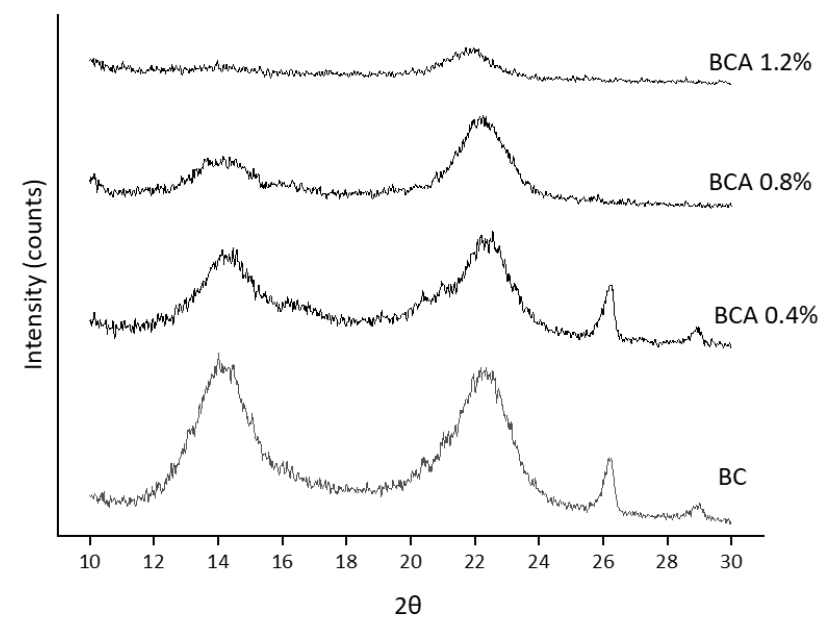

Figure 3. X-ray diffraction pattern of $\mathrm{BC}$ with different concentrations of alginate

Table 1. Opacity, crystallinity and crystallite size of BC with different concentration of alginate

\begin{tabular}{cccc}
\hline $\begin{array}{c}\text { Alginate content } \\
(\% \mathrm{w} / \mathrm{v})\end{array}$ & Opacity & $\begin{array}{c}\text { Crystallinity } \\
(\%)\end{array}$ & $\begin{array}{c}\text { Crystallite size } \\
(\mathrm{nm})\end{array}$ \\
\hline 0.0 & $75.74 \pm 1.39^{\mathrm{b}}$ & 90.63 & 3.06 \\
0.4 & $60.21 \pm 4.06^{\mathrm{b}}$ & 84.47 & 2.60 \\
0.8 & $64.38 \pm 2.74^{\mathrm{b}}$ & 82.70 & 2.50 \\
1.2 & $35.61 \pm 2.14^{\mathrm{a}}$ & 70.16 & 2.23 \\
\hline
\end{tabular}

Different superscript within a column with different letters indicate significant difference $\mathrm{p}<0.05$

Sya'di et al. (2017) explained the increased concentration of polysaccharides added to the medium resulted in a greater inhibitory effect on the BC aggregation process, thereby reducing the crystallinity of the $\mathrm{BC}$ obtained. There are many factors that affected the formation of microfibrils from BC. During the crystallization process of $\mathrm{BC}$, cellulose molecules interact with each other and form certain arrangements through hydrophobic interactions to form molecular sheets, wherein later these sheets are associated with each other through hydrogen bonds to form crystals 
(Haigler et al., 1980). Alginate is likely to disturb the hydrophobic interaction which ultimately results in lower crystallinity with increased alginate concentration.

\subsection{Water vapour permeability}

Food product packaging is demanded to have the ability to limit the mass transfer of water vapour between the product being packaged with the surrounding environment. WVP testing is a standard method to determine the ability of packaging material to act as a barrier to water vapor by analysing the water permeation that passes through the packaging material. Table 2 shows that the addition of alginate up to $0.8 \%(\mathrm{w} / \mathrm{v})$ to the G. xylinus growth medium caused an increase in WVP in the resulting BCA composite. Alginates are very hydrophilic, so they possess a low water vapour barrier characteristic (Olivas and Barbosa-Cánovas, 2008). This results in the formation of a strong interaction between water molecules with functional groups - COO- and $\mathrm{OH}$. More and more water molecules are bound to the surface of the film creating a driving force in the form of a concentration gradient in the film layer and causing an increase in water transfer through the film (Phisalaphong et al., 2008). This result is consistent with SEM test results that show the rough surface structure of the BCA films of 0.4 and $0.8 \%(\mathrm{w} / \mathrm{v})$. GhasemLou et al. (2011) reported that the rough surface of the film made from soybean polysaccharides is a binding site for water during the process of water absorption. Different things happen with the addition of $1.2 \%(\mathrm{w} / \mathrm{v})$ alginate where a strong hydrogen bond is formed between alginate and bacterial cellulose, thus limiting the interaction between alginate and water and ultimately reducing the movement of water through the film layer (Wang et al., 2018).

\subsection{Mechanical properties}

The addition of alginate caused a decrease in the tensile strength and tear strength of the BCA films produced (Table 2). Similar results have been reported by Phisalaphong et al. (2008), Kanjanamosit et al. (2010) and Chiaoprakobkij et al. (2011), where the addition of alginate results in a decrease in the mechanical properties of the resulting bacterial cellulose film. The change in mechanical properties is caused by the termination of intermolecular hydrogen bonds in cellulose in the formation of BCA biocomposites (Chiaoprakobkij et al., 2011). The decrease of tensile and tear strength is also in line with the decrease of crystallinity of biocomposites, thus indicating that decreasing tensile strength may be associated with the decrease of crystallinity. An increase in alginate concentration did not have a significant effect on the tensile and tear strength values of the biocomposite produced.

Table 2. Mechanical properties and water vapor permeability (WVP) values of $\mathrm{BC}$ with different concentration of alginate

\begin{tabular}{cccc}
\hline $\begin{array}{c}\text { Alginate } \\
\text { content } \\
(\% \mathrm{w} / \mathrm{w})\end{array}$ & $\begin{array}{c}\text { Tensile } \\
\text { Strength } \\
(\mathrm{MPa})\end{array}$ & $\begin{array}{c}\text { Tear Strength } \\
(\mathrm{kgf} / \mathrm{cm})\end{array}$ & $\begin{array}{c}\text { WVP } \times 10^{-11} \\
(\mathrm{~g} / \mathrm{Pa} . \mathrm{s} . \mathrm{m})\end{array}$ \\
\hline 0.0 & $113.88 \pm 8.25^{\mathrm{c}}$ & $5.52 \pm 1.64^{\mathrm{b}}$ & $2.41 \pm 0.16^{\mathrm{b}}$ \\
0.4 & $57.76 \pm 4.39^{\mathrm{b}}$ & $2.70 \pm 0.58^{\mathrm{a}}$ & $2.64 \pm 0.23^{\mathrm{b}}$ \\
0.8 & $26.28 \pm 7.43^{\mathrm{a}}$ & $1.66 \pm 0.22^{\mathrm{a}}$ & $3.7 \pm 0.406^{\mathrm{c}}$ \\
1.2 & $21.89 \pm 3.27^{\mathrm{a}}$ & $2.65 \pm 0.14^{\mathrm{a}}$ & $1.81 \pm 0.15^{\mathrm{a}}$ \\
\hline
\end{tabular}

Different superscript within a column with different letters indicate significant difference $\mathrm{p}<0.05$

\subsection{Opacity}

Opacity is a common measurement to determine the transparency of a film. High opacity values indicate low transparency, and vice versa (Atef et al., 2014). Table 1 shows that the BC opacity was not significantly different from the BCA 0.04 and $0.8 \% \mathrm{w} / \mathrm{v}$. Several things affect the optical properties of a film, including thickness, fibre size, and surface morphology (Lin et al., 2019). A rough film surface can affect the scattering of light (Zhu et al., 2013) thus affecting the optical properties of the film. Based on SEM photo results, BCA 0.4 and $0.8 \% \mathrm{w} / \mathrm{v}$ showed a rough surface morphology, thus affecting the high opacity of the film and low transparency. At the use of $1.2 \% \mathrm{w} / \mathrm{v}$ alginate, the opacity value is much lower than $\mathrm{BC}$, indicating higher transparency in the film obtained. This indicates that alginates were well distributed on the $\mathrm{BC}$ matrix as evidenced by SEM photo results, resulting in a homogeneous and transparent film.

\section{Conclusion}

The addition of alginate to the growth media of cellulose-producing bacteria provided many advantageous properties to the biocomposite produced. Alginate shows good interaction with bacterial cellulose matrix through the formation of hydrogen bonds between cellulose molecules and alginate. The significant improvement in terms of water vapor permeability and transparency were apparently obtained from the addition of $1.2 \% \mathrm{w} / \mathrm{v}$ alginate. This research shows that biocomposite film based on bacterial cellulose and alginate is very potential as a packaging material for food products.

\section{Conflict of interest}

The authors declare no conflict of interest.

\section{Acknowledgments}

This research was sponsored by the Educational Fund Management Institute (LPDP), Ministry of Finance 
of the Republic of Indonesia within the framework of the 2016 BUDI DN program.

\section{References}

ASTM. (1995). ASTM E 96 - 95. Standard Test Method for Water Vapor Transmissions for Materials. West Conshohocken, PA, USA: American Society for Testing and Materials.

ASTM. (2002). ASTM D 1746 - 97. Standard Test Method for Transparency of Plastic Sheeting. West Conshohocken, PA, USA: American Society for Testing and Materials.

Atef, M., Rezaei, M. and Behrooz, R. (2015). Characterization of physical, mechanical, and antibacterial properties of agar-cellulose bionanocomposite films incorporated with savory essential oil. Food Hydrocolloids, 45, 150-157. https://doi.org/ 10.1016/j.foodhyd.2014.09.037

Ben-Hayyim, G. and Ohad, I. (1965). Synthesis of Cellulose by Acetobacter xylinum: VIII. On the formation and orientation of bacterial cellulose fibrilsin the presence of acidic polysaccharides. Journal of Cell Biology, 25(2), 191-207. https:// doi.org/10.1083/jcb.25.2.191

Cazon, P., Velazquez, G., Ramírez, J.A. and Vázquez M. (2017). Polysaccharide-based films and coatings for food packaging: a review. Food Hydrocolloids, 68, 136-148.

j.foodhyd.2016.09.009

Chiaoprakobkij, N., Sanchavanakit, N., Subbalekha, K., Pavasant, P. and Phisalaphong, M. (2011). Characterization and biocompatibility of bacterial cellulose/alginate composite sponges with human keratinocytes and gingival fibroblasts. Carbohydrate Polymers, 85(3), 548-553. https://doi.org/ 10.1016/ j.carbpol.2011.03.011

Cienchanska, D. (2004). Multifunctional bacterial cellulose/chitosan composite materials for medical applications. Fibres and Textiles in Eastern Europe, 12(4), 69-72. https://doi.org/ 10.1.1.471.9652.

Debeaufort, F., Quezada-Gallo, J.A. and Voilley, A. (1998). Edible films and coatings: tomorrow's packagings: a review. Critical Review on Food Science and Nutrition, 38(4), 299-313. https:// doi.org/ 10.1080/10408699891274219

GhasemLou, M., Khodaiyan, F. and Oromiehie, A. (2011). Rheological and structural characterization of film-forming solutions and biodegradable edible film made from kefiran as affected by various plasticizer types. International Journal of Biological Macromolecules, 49(4), 814 - 821. https://doi.org/ 10.1016/j.ijbiomac.2011.07.018
Gholamipoor, S., Nikpour-Ghanavati, Y., Oromiehie, A.R. and Mohammadi, M. (2013). Extraction and Characterization of Alginate from Sargassum angustifolium Collected from Northern Coasts of Persian Gulf, Bushehr, presented at the 7th Symposium on Advances in Science and Technology, Bandar Abbas City, 2013. Bandar Abbas, Iran: Civilica Publishing.

Grande, C.J., Torres, F.G., Gomez, C.M., Troncoso, O.P., Canet-Ferrer, J. and Martinez-Pastor, J. (2009). Development of self-assembled bacterial cellulose starch nanocomposites. Materials Science and Engineering C, 29(4), 1098-1104. https://doi.org/ 10.1016/j.msec.2008.09.024

Haigler, C., Brown, R. and Benziman, M. (1980). Calcofluor white ST Alters the in vivo assembly of cellulose microfibrils. Science, 210(4972), 903-906. https://doi.org/10.1126/science.7434003

Hestrin, S. and Schramm, M. (1954) Synthesis of cellulose by Acetobacter xylinum. 2. Preparation of freeze-dried cells capable of polymerizing glucose to cellulose. Biochemical Journal, 58(2), 345-352. https://doi.org/10.1042/bj0580345

Hirai, A., Tsuji, M. and Horii, F. (1997). Communication: culture conditions producing structure entities composed of Cellulose I and II in bacterial cellulose. Cellulose, 4, 239-245. https:// doi.org/10.1023/A.1018439907396

Kanjanamosit, N., Muangnapoh, C. and Phisalaphong, M. (2010). Biosynthesis and characterization of bacteria cellulose-alginate film. Journal of Applied Polymer Science, 115(3), 1581-1588. https:// doi.org/10.1002/app.31138

Lin, C., Qinhua Wang, Q., Deng, Q., Huang, H., Huang, F., Huang, L., Ni, Y., Chen, L., Cao, S. and Ma, X. (2019). Cellulose, 26(1), 4061-4069. https:// doi.org/10.1007/s10570-019-02367-3

Martins, I.M.G., Magina, S.P., Oliveira, L., Freire, C.S.R., Silvestre, A.J.D., Neto, C.P. and Gandini, A. (2009). New biocomposites based on thermoplastic starch and bacterial cellulose. Composites Science and Technology, 69(13), 2163-2168. https:// doi.org/10.1016/j.compscitech.2009.05.012

Miao, C. and Hamad, W.Y. (2013). Cellulose reinforced polymer composites and nanocomposites: a critical review. Cellulose, 20, 2221-2262. https:// doi.org/10.1007/s10570-013-0007-3

Olivas, G.I. and Barbosa-Cánovas, G.V. (2008). Alginate -calcium films: Water vapor permeability and mechanical properties as affected by plasticizer and relative humidity. LWT-Food Science and Technology, 41(2), 359-366. https://doi.org/10.1016/ 
j.lwt.2007.02.015

Phisalaphong, M., Suwanmajo, T. and Tammarate, P. (2008). Synthesis and Characterization of Bacterial Cellulose/Alginate Blend Membranes. Journal of Applied Polymer Science, 107(5), 3419-3424. https://doi.org/10.1002/app.27411

Rhim, J., Park, H. and Ha, C. (2013). Bionanocomposites for food packaging applications. Progress in Polymer Science, 38(10-11), 16291652. https://doi.org/10.1016/ j.progpolymsci.2013.05.008.

Ruka, D.R., Simon, G.P. and Dean, K.M. (2012). Altering the growth conditions of Gluconacetobacter xylinus to maximize the yield of bacterial cellulose. Carbohydrate Polymers, 89(2), 613-622. https:// doi.org/10.1016/j.carbpol.2012.03.059

Seifert, M., Hesse, S., Kabrelian, V. and Klemm, D. (2004). Controlling the water content of never dried and reswollen bacterial cellulose by the addition of water-soluble polymers to the culture medium. Journal of Polymer Science Part A: Polymer Chemistry, 42(3), 463-470. https://doi.org/10.1002/ pola. 10862

Sya'di, Y.K., Wahyuni, E.T., Rahayu, E.S., Cahyanto, M.N. (2017). The effect of polysaccharide in the fermentation medium on physical properties of bacterial cellulose from Gluconacetobacter xylinus BTCC B796. Pakistan Journal of Biotechnology, 14 (3), 323-327.

Ul-Islam, M., Khan, T. and Park, J.K. (2012). Nanoreinforced bacterial cellulose montmorillonite composites for biomedical applications. Carbohydrate Polymers, 89(4), 1189-1197. https:// doi.org/10.1016/j.carbpol.2012.03.093

Vargas, M., Pastor, C., Chiralt, A., McClements, D.J. and González-Martínez, C. (2008). Recent advances in edible coatings for fresh and minimally processed fruits. Critical Review on Food Science, 48(6), 496511. https://doi.org/10.1080/10408390701537344

Villalobos, R., Chanona, J., Hernandez, P., Gutiaerrez, G. and Chiralt, A. (2005). Gloss and transparency of hydroxypropyl methylcellulose films containing surfactants as affected by their microstructure. Food Hydrocolloids, 19(1), 53-61. https://doi.org/10.1016/ j.foodhyd.2004.04.014

Wang, X., Guo, C., Hao, W., Ullah, N., Chen, L., Li, Z. and Feng, X. (2018). Development and characterization of agar-based edible films reinforced with nano-bacterial cellulose. International Journal of Biological Macromolecules, 118(Part A), 722-730. https://doi.org/10.1016/ j.ijbiomac.2018.06.089
Xiang, C. and Acevedo, N.C. (2017). In situ selfassembled nanocomposites from bacterial cellulose reinforced with electrospun poly (lactic acid)/lipid nanofibers. Polymers, 9(5), $179 . \quad \mathrm{https} / /$ doi.org: 10.3390/polym9050179

Yang, G., Zhang, L., Peng, T. and Zhong, W. (2000). Effect of $\mathrm{Ca}^{2+}$ bridge crosslinking on structure and pervaporation of cellulose/alginate blend membranes. Journal of Membrane Science, 175(1), 53-60. https://doi.org/10.1016/S0376-7388(00)00407 $-5$

Zhou, L.L., Sun, D.P., Hu, L.Y., Li, Y.W. and Yang, J.Z. (2007). Effect of addition of sodium alginate on bacterial cellulose's production by Acetobacter xylinum. Journal of Industrial Microbiology and Biotechnology, 34(7), 483-489. https:// doi.org/10.1007/s10295-007-0218-4

Zhu, H.L., Parvinian, S. and Preston, C. (2013). Transparent nanopaper with tailored optical properties. Nanoscale, 5(9), 3787-3792. https:// doi.org/10.1039/c3nr00520h 